\title{
Individual Time Preferences and Energy Efficiency
}

\author{
By Richard G. Newell and Juha SiIKAMÄKl*
}

A large literature examines energy-efficiency investments by consumers and firms, particularly evaluation of the extent of and explanations for an "energy efficiency (EE) gap" (Gerarden, Newell, and Stavins 2015). But prior studies have not considered the role of individual discount rates in such decisions. Instead, most assessments assume a certain discount rate against which the rationality of observed choices is gauged (Allcott and Wozny 2014), or alternatively, estimate aggregate discount rates that best match observed EE decisions, conditional on an assumed decision model (Hausman 1979).

The absence of evidence on the role of individual discount rates is surprising because the profitability of EE investments depends fundamentally on the rate at which individuals discount future energy savings relative to the required upfront investment. The potential importance of individual discount rates is further heightened by findings in experimental studies that elicited time preferences exhibit considerable heterogeneity (Frederick, Loewenstein, and O'Donoghue 2002).

This paper broadly examines the role of individual discount rates in EE decisions. Our earlier findings on information provision (Newell and Siikamäki 2014-henceforth, NS) indicate that the efficacy of alternative labels in guiding cost-efficient decisions depends critically on the discount rate used for analysis. Here we closely examine individual discount rates as a determinant of the value households place on future energy savings.

Our results demonstrate that individual discount rates exhibit considerable heterogeneity

\footnotetext{
* Newell: Duke University, Box 90467 Durham, NC 27708 (e-mail: richard.newell@ duke.edu); Siikamäki: Resources for the Future, 1616 P St. NW, Washington, DC 20036 (e-mail:juha@rff.org). The research was supported by EPA STAR Grant 83285101 .

${ }^{\dagger}$ Go to http://dx.doi.org/10.1257/aer.p20151010 to visit the article page for additional materials and author disclosure statement $(\mathrm{s})$.
}

and systematically influence household willingness to pay (WTP) for EE, as measured through product choices, required payback periods, and EE tax credit claims. The relationship is statistically significant, empirically robust, and not confounded by the characteristics of the homeowner, household, and their home. We also examine the determinants of individual discount rates to better understand what drives their substantial heterogeneity: education, household size, race, credit score, and to some extent income, are important factors. Overall, our findings imply that individual discount rates are critical to understanding EE investments, the "EE gap," and to guiding policy on EE.

\section{Household Survey}

We draw evidence from extensive survey results from 1,217 random single family US homeowners (see NS for details) 1 A key part of the survey included choice experiments to estimate WTP for EE. Using a computerized survey instrument, each study participant faced several decisions involving choosing the preferred product from three different appliance options. The specific choice problem was a water heater purchase, which provides a range of distinct advantages.

We administered 12 randomized label treatments that altered the type of available EE information. The choice experiments examined many alternative product models across the respondents and labeling treatments so that elicited data enable estimation of the implicit trade-off between the purchase cost and annual energy operating cost of the appliance.

The survey elicited individual discount rates using a method common to experimental economics (Coller and Williams 1999). Moreover,

\footnotetext{
${ }^{1}$ We fielded the survey using a random sample from the GfK panel. It is designed to be representative of the United States and is widely used for research in many fields.
} 
it collected rich data on the characteristics and life situation of the homeowner, household, and their home.

\section{Labels, WTP for EE, and Discounting}

The experiment setting and econometric approach enable disentangling the relative importance of different types of information on labels in guiding EE behavior, and distinguishing it from intertemporal behavior.

Using choice data in combination with the random utility and multinomial logit models, NS directly estimate WTP for reductions in the present value of operating costs (PVOC) so that one can readily examine whether households under- or overvalue energy savings. For cost-minimizing energy decisions a household should be willing to pay one dollar more in purchase cost for each dollar of reduced PVOC. NS model WTP for reduced PVOC as a function of information treatments to directly estimate how much the labeling attributes contribute to the valuation of PVOC.

NS find that the information content and label style strongly influence the valuation of $\mathrm{EE}$ and that a lack of relevant information leads to significant undervaluation of EE. 2

The degree to which the current US EnergyGuide label guided cost-efficient decisions depends importantly on the discount rate assumed appropriate for the analysis. Using individual discount rates elicited in the survey, NS find the current EnergyGuide label came very close to guiding cost-efficient decisions, on average. However, using a uniform five percent discount rate-typical of government regulatory analysis, but much lower than the average individual elicited rate - the EnergyGuide label led to choices resulting in a one-third undervaluation of EE. These results reinforce the importance of intertemporal choice and discounting both for understanding individual behavior and for guiding policy decisions.

\footnotetext{
${ }^{2}$ Providing simple information on the economic value of saving energy was the most important element guiding more cost-efficient investments in EE, with information on physical energy use and carbon emissions having additional but lesser importance.
}

\section{Time Preferences and EE Choices}

\section{A. Individual Time Preferences}

We elicited individual discount rates using an experiment where the respondent chose between a $\$ 1,000$ payment available in one month and a higher payment available in 12 months ${ }^{3}$ The elicited discount rates indicate considerable heterogeneity (online Appendix Figure A1), and are generally consistent with other similar experimental evidence (see NS for a more detailed review). The mean rate was 19 percent, the median was 11 percent, and the standard deviation was 23 percent. The distribution has a concentration at relatively low discount rates $(\leq 10$ percent $)$ and is skewed right with a few observations at high rates ( $\geq 40$ percent). An advantage of our sample is that it is more representative of the population than is typical of the time preference elicitation literature; this breadth also allows for exploration of the effect of demographic variables (see Section IV).

\section{B. WTP for EE Investments}

Next, we examine individual time preferences as a determinant of households' WTP for annual energy savings, using data from the appliance choice experiments described earlier. Our empirical model follows the random utility model (see NS) with a linear additive structure written to directly estimate WTP for annual operating cost (OC):

$$
U_{i j}=\lambda_{i}\left(p_{i j}+\gamma_{i} O C_{i j}\right)+\varepsilon_{i j},
$$

where $U_{i j}$ denotes the utility that person $i$ derives from alternative $j, \lambda_{i}$ is the marginal utility of income estimated on $p_{i j}$, the price of alternative $j$, and $\varepsilon_{i j}$ is a random variate (i.i.d. extreme value). The term $\gamma_{i}$ is the WTP for annual operating cost. To model factors affecting WTP, we reparameterize $\gamma_{i}$ as

$$
\gamma_{i}=\hat{\gamma} \exp \left(\beta R_{i}+\phi X_{i}\right)
$$

\footnotetext{
${ }^{3}$ Using a method based on Coller and Williams (1999), we administered a series of questions where each respondent who chose the near term payment $(\$ 1,000)$ continued through new choices with a larger 12-month payment, until the respondent switched from choosing the near term payment to the 12-month payment.
} 
Table 1- Estimated Coefficient on Individual Discount Rate when Predicting Preferences for EE

\begin{tabular}{|c|c|c|c|c|}
\hline & $\begin{array}{l}\text { Choice-based } \\
\text { WTP for } \$ 1 \text { annual } \\
\text { energy savings }{ }^{\mathrm{a}}\end{array}$ & $\begin{array}{c}\text { Stated WTP } \\
\text { for } \$ 10 \text { annual } \\
\text { energy savings }\end{array}$ & $\begin{array}{l}\text { Payback } \\
\text { period } \\
\text { required }^{\mathrm{c}}\end{array}$ & $\begin{array}{c}\text { Federal } \\
\text { EE tax credit } \\
\text { claims }\end{array}$ \\
\hline Model $1(\text { most restricted model })^{\mathrm{e}}$ & $-0.017 * * *$ & $-0.100 * * *$ & $-0.076 * * *$ & $-0.028 *$ \\
\hline Model 2 (more flexible than Model 1) & $-0.016^{* *}$ & $-0.100 * * *$ & $-0.075^{* * * *}$ & $-0.024 *$ \\
\hline Model 3 (more flexible than Model 2) & $-0.016^{* * *}$ & $-0.080 * *$ & $-0.061 * * *$ & -0.019 \\
\hline Model 4 (most flexible model ) & $-0.016^{* * *}$ & $-0.079 * *$ & $-0.046^{*}$ & -0.017 \\
\hline
\end{tabular}

Notes: See NS for the description of the survey experiments.

${ }^{a}$ Estimated using an exponential specification (see equation (2)). See online Appendix Table A2 for other results.

${ }^{\mathrm{b}}$ OLS to predict the maximum amount (dollars in logs) the respondent is WTP for every $\$ 10$ reduction in the annual energy cost of a water heater. See online Appendix A3 for other results.

${ }^{\mathrm{c}}$ OLS to predict the length of time (years in logs) the respondent listed when asked how quickly a more energy-efficient water heater alternative should recover its additional purchase cost through energy savings. See online Appendix Table A4 for other results.

${ }^{\mathrm{d}}$ A linear probability model to predict the likelihood the household claimed the federal EE tax credit. See online Appenidx Table $5 \mathrm{~A}$ for other results.

${ }^{\mathrm{e}}$ Model specifications vary by model type and dependent variable. See the online Appendix for detailed model specifications. *** Significant at the 1 percent level.

** Significant at the 5 percent level.

* Significant at the 10 percent level.

where $R_{i}$ is the individual specific discount rate for person $i$ and $X_{i}$ is a vector of variables which denote the characteristics and situation of the homeowner, household, and their home. $X_{i}$ also includes as controls seven binary indicators of the information treatment person $i$ received. The specification allows direct estimation of the effect of individual time preferences on WTP for $\mathrm{EE}$, controlling for other possible determinants 4

We estimate several empirical specifications ranging from a simple model that includes only the purchase and operating cost of choice alternatives (Model 1), to gradually more flexible and comprehensive specifications that incorporate the characteristics of the homeowner, household, and their home (Model 2), and information treatments (Model 3). Finally, we add a random element to the purchase cost parameter to address any heterogeneity remaining after inclusion of observed heterogeneity (Model 4).

The estimation results indicate a robust and statistically significant relationship between individual discount rates and WTP for EE (Table 1, column 1; details in online Appendix A2). Different model specifications estimate the coefficient $\beta$ at almost exactly the same magnitude, indicating that WTP for annual operating

\footnotetext{
${ }^{4}$ We also control for the nonmonetary attributes of the choice alternatives but exclude them in equation (1) for brevity.
}

cost savings declines by about 1.6 percent for each percentage point increase in the individual's discount rate. This is intuitive: for individuals with higher discount rates the value of reduced future operating costs is lower, as is their WTP for EE.

The robustness of the estimation results across different specifications suggests individual discount rate heterogeneity affects WTP independent of the characteristics of the homeowner, household, and their home 5

The survey also asked respondents directly to state their maximum WTP for a $\$ 10$ reduction in annual energy costs (see the online Appendix). OLS estimation results show a robust, statistically significant association between the individual discount rate and WTP for EE (both in logs). The coefficient on the individual discount rate (Table 1, column 2; details in online Appendix Table A3), indicates that the elasticity of WTP with respect to the discount rate is about -0.08 to -0.10 . This result is consistent qualitatively with the findings based on the more detailed choice experiment (equations (1) and (2)).

\footnotetext{
${ }^{5}$ We consider an extensive set of variables to denote such conditions (online Appendix Table A1), including data on the age, education, ethnic background, gender, and employment status of the head of household; number of children; household size, income, and likelihood of moving; number of bedrooms; whether the home has a new water heater; and US geographic location (East, Midwest, South, West).
} 


\section{Payback Period Required for EE Investments}

The survey also directly asked respondents their "payback" preferences-how quickly a more EE water heater should recover its additional purchase price through energy savings to remain attractive (see the online Appendix). Respondents stated a mean and median payback threshold of 3.5 years, with a standard deviation of 1.9 years. Again, OLS estimation results show a consistent and statistically significant association between the individual discount rate and payback years (both in logs). The coefficient on the individual discount rate (Table 1, column 3; details in online Appendix Table A4) indicates that the elasticity of payback period with respect to the discount rate is roughly -0.05 to -0.08 . The finding is again consistent with expectations: the greater the discount rate, the shorter the time horizon required for the investment to break even.

\section{Tax Credits for EE Investments}

Federal tax credits to promote household investments in EE were in place from 20062011. These credits were popular, with 23 percent of single family homeowners in our sample taking advantage of the credits. We examine the factors determining who claimed EE tax credits, with particular interest in whether individual discount rates are associated with tax credit claims. ${ }^{6}$ The estimation results indicate that the likelihood of claiming a tax credit is systematically associated with lower individual discount rates, higher household income, and a lower likelihood of moving (Table 1, column 4; details in online Appendix Table A5). The likelihood of claiming the tax credit increases as the individual discount rate decreases. This is as expected because WTP for EE is higher for households with relatively low discount rates, so they are higher on the demand curve for EE investments.

\footnotetext{
${ }^{6} \mathrm{We}$ examine this using a simple linear probability model, which includes the individual discount rate as a predictor along with other drivers of the tax credit choice, including income, likelihood the household will move, and various homeowner attributes.
}

\section{Influence of Individual Characteristics on Their Time Preferences}

Next, we examine the determinants of individual discount rates using observable characteristics of the head of household, the household, and their home as predictors in a wide array of regression specifications? ${ }^{7}$

One of the most consistent results (online Appendix Table A6) is that education matters greatly for individual discount rates. Controlling for other factors, individuals with some college education have discount rates 8-9 percentage points lower, and those with at least a bachelor's degree 13-14 percentage points lower, than those with no college (whose mean rate was 24 percent). This result is consistent across models with a wide range of continuous and categorical controls for income and even credit score.

Other consistent determinants of discount rates include household size and race. Larger households and black, non-Hispanic respondents had relatively high discount rates, even after controlling for income, education, and a wide range of other characteristics.

Income has a distinct association with individual discount rates, although this relationship is not always statistically significant. Setting statistical significance aside, we have examined many specifications with fine-grained income category dummies. The magnitude of those estimates suggests that higher incomes tend to be associated with lower discount rates. The results also suggest that the discount rates may spike at very low incomes, below $\$ 10,000$ annually.

Finally, we find that lower credit scores are associated with significantly higher individual discount rates, consistent with the financial interest rates the individual likely faces.

\section{REFERENCES}

Allcott, Hunt, and Nathan Wozny. 2014. "Gasoline Prices, Fuel Economy, and the Energy Paradox." Review of Economics and Statistics 96 (5): 779-95.

\footnotetext{
${ }^{7}$ Other studies have also found that education and income have a negative effect on discount rates (Anderson et al. 2006).
} 
Andersen, Steffen, Glenn W. Harrison, Morten Igel Lau, and E. Elisabet Rutström. 2006. "Elicitation using multiple price list formats." Experimental Economics 9 (4): 383-405.

-Coller, Maribeth, and Melonie B. Williams. 1999. "Eliciting Individual Discount Rates." Experimental Economics 2 (2): 107-27.

-Frederick, Shane, George Loewenstein, and Ted O'Donoghue. 2002. "Time Discounting and Time Preference: A Critical Review." Journal of Economic Literature 40 (2): 351-401.

Gerarden, Todd, Richard G. Newell, and Robert N. Stavins. 2015. "Deconstructing the
Energy-Efficiency Gap: Conceptual Frameworks and Evidence." American Economic Review 105 (5). http://dx.doi.org/10.1257/aer. p20151012.

-Hausman, Jerry A. 1979. "Individual discount rates and the purchase and utilization of energy-using durables." Bell Journal of Economics 10 (1): 33-54.

- Newell, Richard G., and Juha Siikamäki. 2014. "Nudging Energy Efficiency Behavior: The Role of Information Labels." Journal of the Association of Environmental and Resource Economists 1 (4): 555-98. 